\title{
A Comparison of Open Access in Exercise Science Journals: 2010 to 2012
}

\author{
Ben Rattray ${ }^{1, *}, J_{u l i e}$ Cooke $^{1}$, Kasia Bail $^{2}$ and Jamie Ranse ${ }^{2}$ \\ ${ }^{1}$ From the Faculty of Health, University of Canberra, National Institute of Sports Studies and ${ }^{2}$ Discipline of Nursing \& \\ Midwifery, Australia
}

\begin{abstract}
The aim of this study was to complete an audit on the number of open access journals within the discipline of Exercise Science. Publishing in open access journals results in wide dissemination of material in a very short period of time compared with the more traditional way of publishing in a subscription journal. The 2010 ERA journal list, category Human Movement and Sport Science, was initially utilised and then compared with the openness of the same journals in 2012.

In this study journals were audited for their degree of open access, open licensing and open format. Open access relates to the free online availability of research results and hence research publications and in the discipline of exercise science relates to the concept of an idealised level playing field. Open licensing relates to the ability of the consumers to replicate and share those publications freely whilst open format relates to the use of open and transferrable format types. Open access increased $(\mathrm{p}=0.014)$ as did our measurement of open licensing $(\mathrm{p}=0.000)$ and open formats $(\mathrm{p}=0.021)$ between the 2010 and 2012 reviews of the journals in 1106 For code.

This study reveals an increase in the number of Exercise Science journals that have full or partial open access over the two year period and suggests that authors are increasingly adopting peer reviewed open access journal publications. It is evident from this study that the impact of open access journals be assessed and further research into the feasibility of such a rating is imperative.
\end{abstract}

Keywords: Human movement, open access, open format, open licensing, sports science.

\section{INTRODUCTION}

The ability for anyone to freely access information and developments in a field of study has gathered tremendous momentum over the last decade. This movement is termed "open access" and has been defined as: the free (gratis) online availability of the research results, ... provided by authors upon acceptance for publication and made permanently available without restrictions on use [1].

Open access is guided by the primary principle that it will result in wide dissemination and access to the research and scholarly material, which can help inform later work [2]. Recently, this has resulted in a number of government research funding agencies worldwide requiring that their funded research outputs be placed on databases that are freely available to the public who fund the actual research [3, 4]. In the health sciences open access is particularly important for evidence-based [5] or evidence-informed practice [6] for practitioners, students, and researchers. Additionally, the increasing trends of information seeking patients/clients for their own health engagement and selfcare warrant consideration regarding access and equity [7].

*Address correspondence to this author at the University of Canberra, National Institute of Sports Studies Bruce ACT 2614;

Tel: +61 (0) 26201 5145; Fax: +61 (0) 26201 5615;

E-mail: ben.rattray@canberra.edu.au
The exercise sciences are included in the health sciences and there is no less reason to promote open access in this discipline. The exercise sciences are however quite broad, and the application of open access could be viewed differently. The open access of information in the exercise sciences in sport (sport sciences) relates to Olympism concepts of the development of sport for all [8] and the idealised level playing field on which sporting competition is based. In the clinical exercise setting, the concept of open access is perhaps more important to consumers as well as governments due to the health implications, in particular preventative health.

As stated by the Budapest Open Access Initiative [9] there are two pathways to achieve open access in scientific literature: self-archiving in Open archives and publishing in Open Access journals. Self-archiving a version of the article is generally permissible by publishers, but it is the practice of publishing in open access journals which we are interested in. Whilst those working in large government agencies and tertiary institutions often have access to company subscriptions to much of the research literature, many practitioners, and direct consumers of exercise science will not. Further, access to information away from the workplace, when individuals are likely to have the time to pursue research, is even less likely. Consequently, and as discussed previously in a nursing context [10], uninhibited access to information is valuable in addressing evidence/practice gaps and the burgeoning field of knowledge translation. Websites 
that offer lists of open access journals, such as the 'Directory of Open Access Journals' [11] and 'Online Journals' [12] demonstrate that many journals which are categorised as openly accessible are not available in English, nor are peer reviewed. Consequently, it would be valuable to offer an audit of current open access publishing, based on a tertiary system of collation, such as the Excellence in Research for Australia (ERA) initiative which was developed by the Australian Research Council and includes peer reviewed manuscripts categorised by disciplines.

\section{SIGNIFICANCE AND AIMS}

It seems obvious that in order to breach the evidence to practice gaps and enhance knowledge transfer, published research should be presented in plain language and in accessible formats [13]. Whilst this remains an important concept, the first step is to allow access to information with minimal inhibitions. This project focuses on physical access (open access and format) and dissemination (licensing issues and format) capabilities of these journals, with an aim to determine:

1. The proportion of exercise science journals that are fully open access or have some elements of open access, and

2. A further aim was to determine if open access practices amongst these journals changed over a set period.

The focus of this research is on the 2012 data collection / analysis as this provides the most recent insight into the open access of journals in this discipline, and the value of the comparison is to observe trends over time.

\section{METHOD}

\section{Design}

This research was non-experimental, simple descriptive in design [14]. This project reports on part of a larger project that aimed to explore and describe the openness of journals across a number of disciplines including midwifery, nursing, psychology, education, government, and nutrition in Australia. The process described below outlines the method used for the exercise science subproject.

\section{Population}

The population for this project was all journals listed on the Excellence in Research for Australia, Australian Research Council (ARC) website [15]. This information was available in a downloadable Microsoft Excel format, and included details such as the journal name, and up to three Field of Research (FoR) codes. In total, this list included 20,712 Australian and international journals. The ERA list was chosen over Journal Citation Reports ${ }^{\circledR}$ (JCR) as the ERA list drives researchers' decision in Australia due to its link to the value of the research output.

\section{Sample}

The sample for this project included all journals that had a primary FoR code of 1106 . This FoR code relates to journals classified as having the largest component of research from, or being most relevant to, the human movement and sports science discipline [15]: in total this included 132 journals. Journals with an FoR of 1106 as either their secondary or tertiary field were excluded from this project in order to keep the focus on practices within this FoR code. Whilst the rankings within the ERA journal list have since been abandoned [16], we chose to analyse journals using the original ranking system as a pseudo for journal quality. The rankings were categorised as 'A', 'B' or ' $\mathrm{C}$ ' based on the perceived prestige of the journal. Those considered the most prestigious were ranked 'A', and the least, but still listed within the ERA, as ' $\mathrm{C}$ '.

\section{Data Collection}

Data was collected from the official website of each listed journal during October 2010, and entered into a Microsoft Excel spread sheet. This process was repeated in May 2012 to encapsulate a period in which significant government funding bodies had discussed and promoted public access to research funded under their schemes [3, 4]. If a journal had ceased publishing since the 2010 study or was unable to be located on the internet or was not published in English it was excluded from the study. Information was collected and related to predetermined elements of openness. In particular, these elements included access, licensing and format. Open access for the purposes of this study refers to materials that are openly accessible online without restriction. Open licensing refers to materials that are freely and legally reproducible, modifiable and redistributable. Open format refers to materials that use open standard and reusable formats such as HTML, ODF, and Ogg. Each journal was coded against these three elements as either being compliant, not compliant or unknown. If the compliance to any element of open access could not be determined or agreed it was assigned as being 'unclear'. In instances where compliance was conditional (e.g. author funded open access) this was considered fully compliant for the 2010 analysis. For further analysis, the 2012 data was separated into fully and partially compliant to these criteria. The reasons for partial compliance were noted and categorised into one of the five reasons noted in Table 1 . Some journals met a number of the partial compliance reasons and all obvious reasons were recorded. For the purposes of comparison, the 2010 data was compared to the fully and partially compliant data from 2012, as these constitute the same methodology. A retrospective breakdown of the 2010 data was not possible.

Our approach was to have two researchers review all the journals and consult on them to reach a verdict. Journal reviews were predominantly made outside the tertiary systems subscriptions and this occurred for all journals in which there were discrepancies between the researchers.

\section{Data Analysis}

Descriptive statistics, such as frequencies, were used to report on the data within the established Microsoft Excel spread sheet. Such descriptive statistics report on the number of journals that have open access, licensing and format. To assess whether the changes in open access were significant over time, we employed the McNemar Test (chi-square) using SPSS version 17 for Windows (SPSS Inc., Chicago, IL, USA) to test the differences between related percentages in our repeated measures design. 


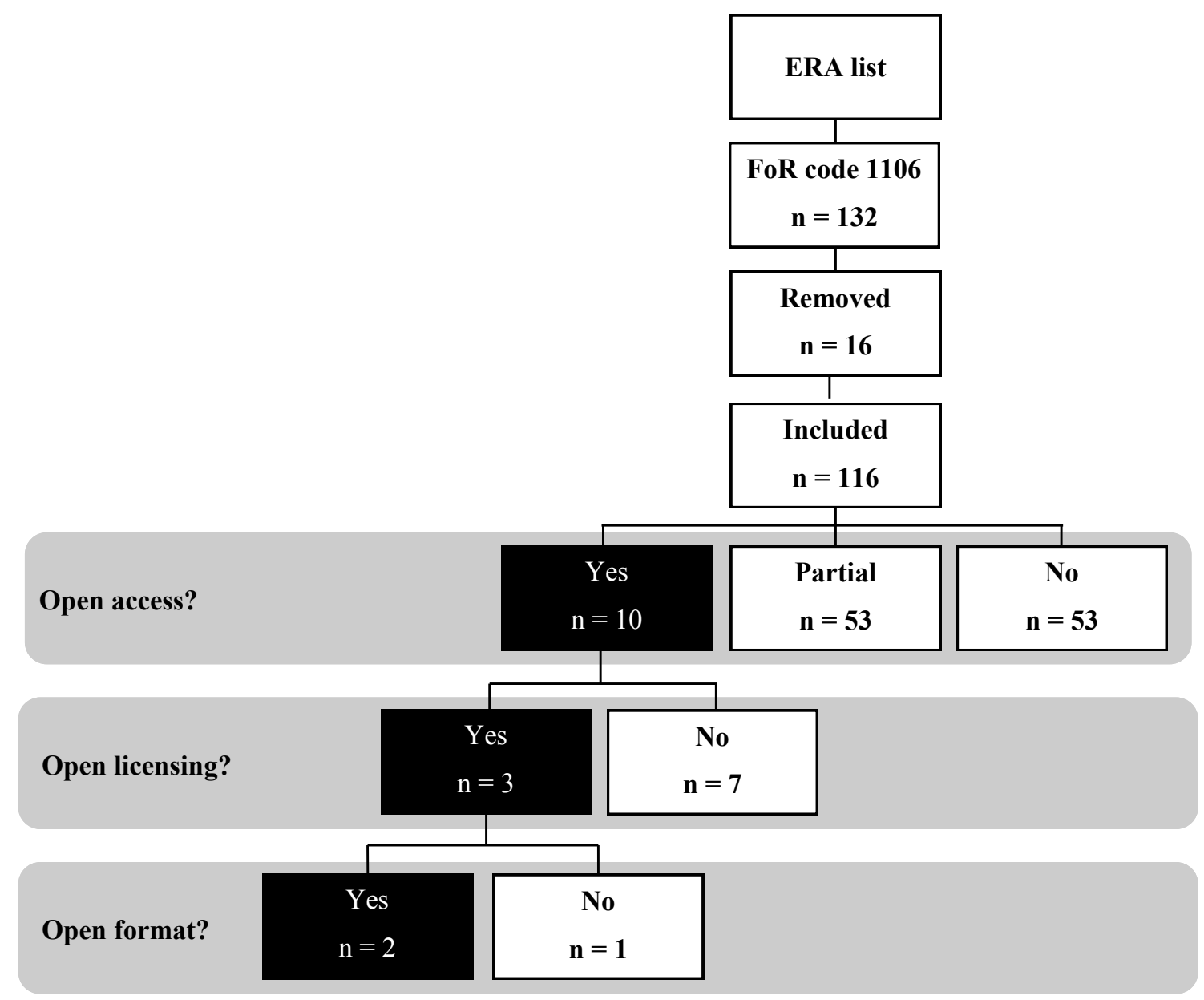

Fig. (1). Number of Human movement and sport sciences (FoR code 1106) journals that are open access, open format and open licensing from the 2012 analysis.

Table 1. Examples of Partial Compliance with Open Access

\begin{tabular}{|l|}
\hline Open Access Restricted to: \\
\hline \hline Release after a certain time frame \\
\hline Selected articles chosen by the journal (e.g. Editor's choice, most popular) \\
\hline Open access after free subscription \\
\hline Paid (author, institution or funder paid open access) \\
\hline Unclear why partial open access to journal \\
\hline
\end{tabular}

\section{Results}

In total, 132 journals were identified that met the research design of this project. Of these, sixteen were removed from the 2012 review. Journals were removed due to ceased publishing, were unable to be located on the internet or were not in English. Subsequently, 116 journals were included in the 2012 analysis (Fig. 1).

\section{Open Access Breakdown}

In the 2012 analysis, only $8.6 \%(10 / 116)$ had unrestricted open access to all published manuscripts, $45.7 \%$ (53/116) had partial or conditional access and $45.7 \%$ (53/116) had no elements of open access unless the consumer had a paid subscription. The reasons for partial open access varied. Of the partial open access journals $(n=53), 34(64 \%)$ of these journals provided open access after the contributor paid for it. It was unclear how partial open access was allocated for $16(30 \%)$ of the journals. Alternate reasons for open access provided in Table 1 accounted for between 3 and 10 journals each. Ten (19\%) of the journals had multiple reasons for their partial open access. Many publishers referred to specific funding bodies regulations when describing the paid open access, such as the National Institute of Health grant funding regulations requiring funded research to be freely accessible. Some publishers noted that payment for publication could be waived if the research originated from low income countries. In some cases, publishers would provide open access to articles with funder requirements after a set time period, typically 6-12 months. 

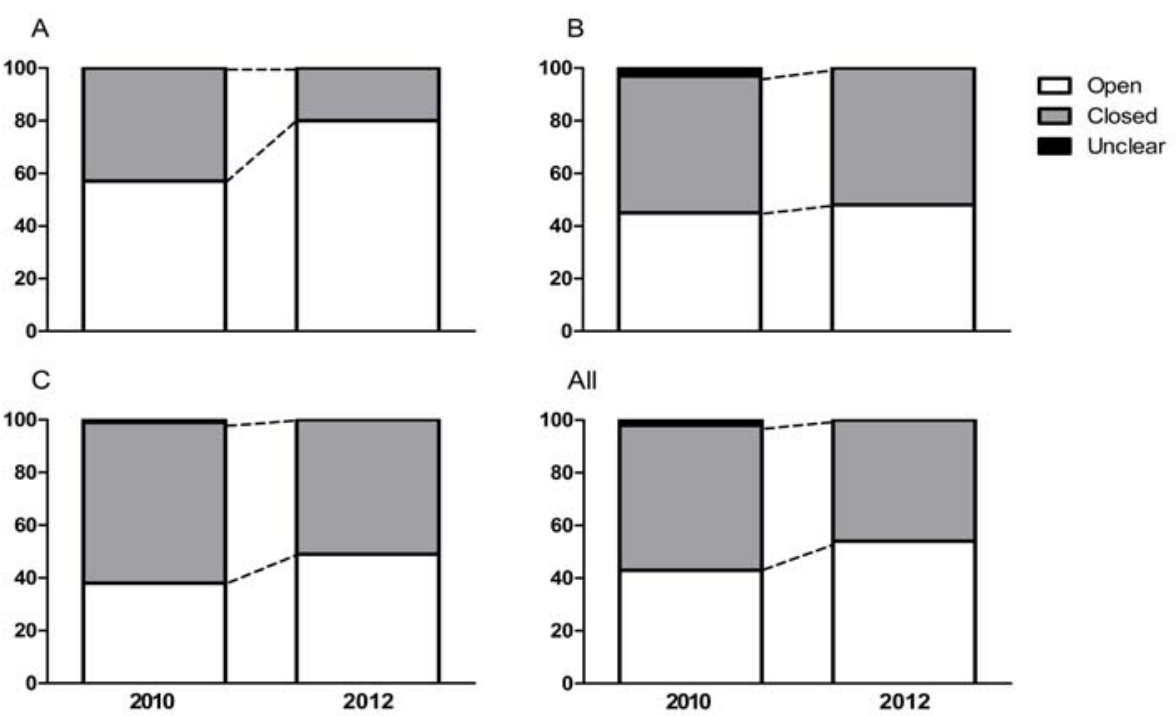

Fig. (2). Percentage of open access journals in the 2010 and 2012 surveys for ERA "A", "B", "C" ranked journals as well as "All". Journals were rated as being open (at least partially), closed, or unclear.
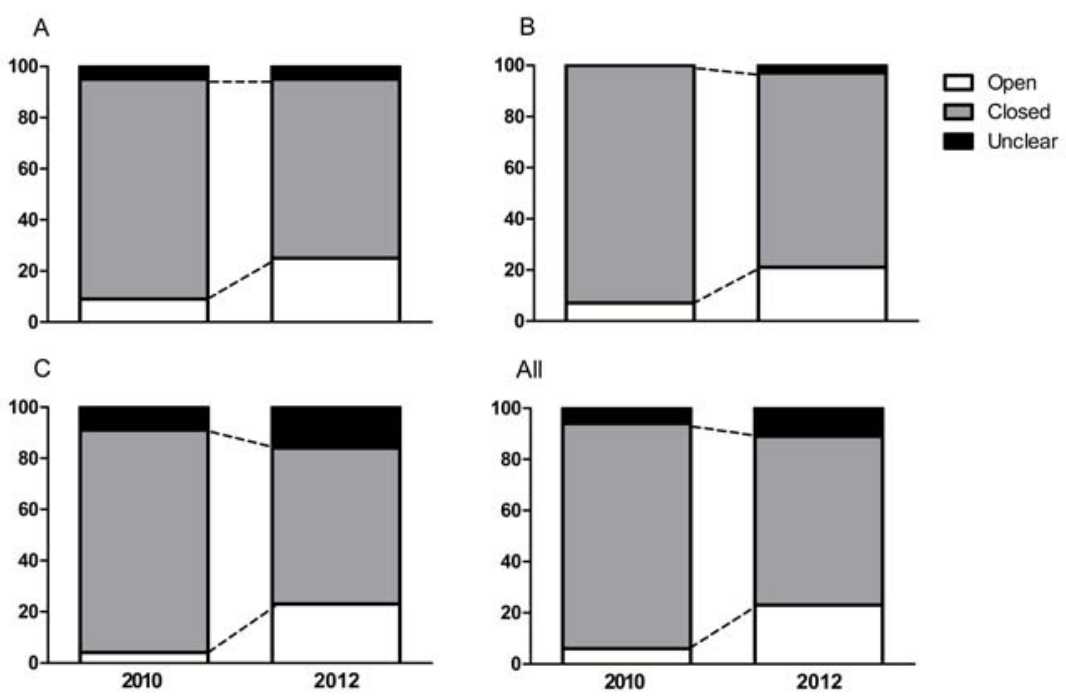

Fig. (3). Percentage of journals rated as having open licensing in the 2010 and 2012 surveys for ERA "A", "B", "C" ranked journals as well as "All". Journals were rated as being open (at least partially), closed, or unclear.

\section{Open Access Changes Over Time}

In order to compare trends in journal changes to open access, the 2012 review was compared to the review carried out in 2010. Thirteen journals were removed from the 2010 review due to similar reasons reported for the 2012 analysis. This left 122 journals for inclusion in the 2010 review. For the comparison over time, journals were judged as being open, not open (closed), or unknown. Partial compliance was considered open in the comparison due to the complexity of developing open access models being engaged over this time period. Results were separated into the rankings of the ERA list as well as overall.

There was increased open access to journals in 2012 compared to $2010 \quad(\mathrm{p}=0.014)$ and this was particularly prominent in "A" and "C" ERA ranked journals (Fig. 2).
When considering A, B and C ERA ranked journals together it can be seen that there was an $11 \%$ increase in openness/partial openness for 2010 to 2012 (Fig. 2).

Licensing relates to the ability of the consumers to replicate and share publications openly, within frameworks such as creative commons [17]. Open licensing was often linked to open access. If the open access was paid for by the contributor, this often also resulted in the granting of a creative commons or similar open licensing agreement. This partial compliance was considered as being open to remain consistent with the open access analysis. The granting of open access licensing options appeared to increase substantially (17\% p=0.000) from 2010 to 2012 (Fig. 3) although the overall open licensing remained below a third of all journals. 

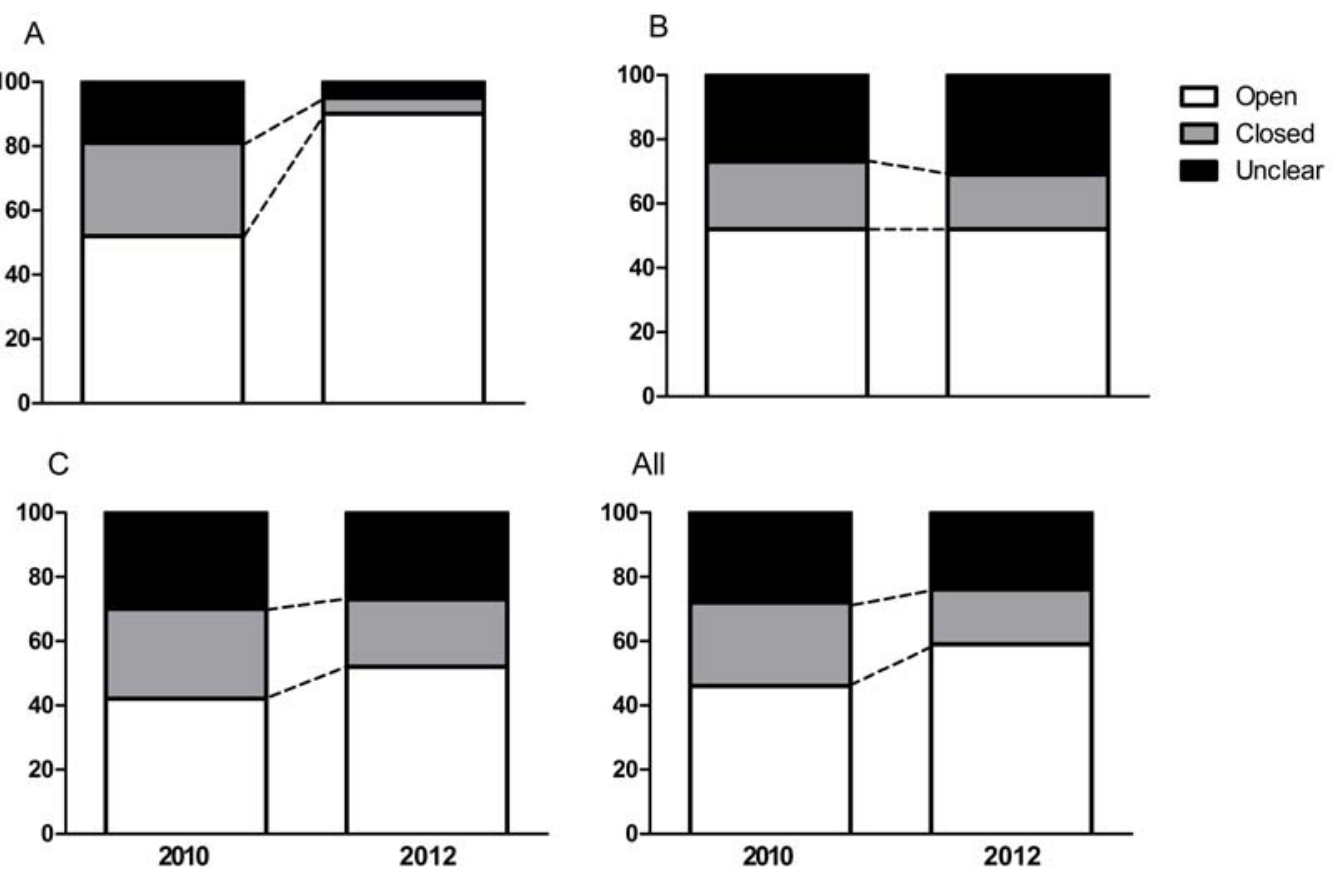

Fig. (4). Percentage of journals rated as having open format in the 2010 and 2012 surveys for ERA "A", "B", "C" ranked journals as well as "All". Journals were rated as being open, closed, or unclear where it could not be ascertained.

There was an increase in the use of open and transferrable format types, such as HTML, within the ERA journal list between 2010 and $2012(\mathrm{p}=0.021)$ which was particularly evident in ERA "A" ranked journals (Fig. 4). PDF format only was not considered compliant to an open format, as PDF requires extended manipulation to share and replicate text when compared to HTML.

\section{DISCUSSION}

This is the first report of open access trends in the exercise science field. We observed a shift in the number of open access opportunities between 2010 and 2012 with a relative increase in 2012 which was particularly apparent in the highest rated ' $A$ ' journals. The increased opportunities to publish open access, often at a cost, between 2010 and 2012 are consistent with annual growth rates for the number of open access journals at $\sim 18 \%$ [18]. However, this is at odds with overall trends in individual publications in the Health Science field where the number of open access publications remained fairly stable at around $17 \%$ between 2005-2010 and back to 1998 [19].

This review reveals a relatively small proportion $(8.6 \%)$ of journals in the human movement and sports science discipline that are fully open access, although many of the discipline journals $(45.7 \%)$ offer conditions under which open access publication could be achieved. Contributor paid open access accounted for $64 \%$ of these partial open access journals. This publisher change in business model probably accounts for most of the overall change in open access opportunities observable between 2010 and 2012 .

The proportion of journals in the exercise sciences we observed as having full or partial open access was similar to what we observed in the nursing literature [10]. This is somewhat surprising as nursing is a larger and more established profession with better understanding within the general population. It was estimated that in $2009,10.6 \%$ of literature classified as 'other areas related to medicine' (13.9\% of the medical literature) was available through open access journals [20]. The exercise sciences and/or journals reviewed in this study have lower open access rates than previous research. This may be due to the relatively small size and demand for research in the field and/or a sign of the low perceived prestige of open access journals. The prestige of all journals in the field was important in the original inclusion of journals within the Excellence in Research Australia (ERA) listings. The authors of this paper are aware of a number of journals that provide full open access and are not listed within the ERA, but seemingly fit under the same umbrella discipline. For instance, only seven of the 58 journals listed under Sports Science on the Directory of Open Access Journals [11] were listed in the ERA list at the time of this survey. This may well be a limitation to this study however in using the ERA list from 2010 and 2012 the authors have retained consistency in the approach. As no previous reports on open access in this scientific field have been published, it is difficult to know how this may have influenced the results.

There appears to be an advantage in publishing individual articles as open access [21, 22]. However, subscription journals still hold, although decreasingly, a scientific impact advantage over open access journals [23]. This is perhaps due to a traditional prestige advantage held by traditional journals. For the contributors though this comes at a cost which for some can be met by their research funders. Many of the larger publishers make provisions related to the change in funding bodies and enable the transfer to an open database. The commercial model for this 
is generally separated into two categories, with a delay in the open release of research, typically 12 months, or more commonly, the payment of a publication fee. In some cases, publishers mention that they will waive these publication fees, generally for contributors from low-income or lowermiddle income countries. Along with contributor paid open access, this payment also often allows for a relaxation in licensing, which is generally an arrangement that is either a creative commons non-commercial use license or similar.

In many cases it is difficult to assess the true nature of open access and the increasing number of ways in which open access is being made available as publishers develop business models to suit this growing area. Our approach in having two researchers review all the journals and consult on them to reach a verdict in some regards minimised this difficulty. In any case, the open access status of journals is not stagnant, and any analysis of this type will only provide an indication of what is occurring across the field of study at a particular point in time. Our decision to retain and analyse according to the now disbanded ERA journal ranking may also be criticised but we chose to take this approach to examine if there was any difference in openness across the rankings. The rankings were originally created by experts in the relative discipline fields [15] and are likely influenced by perceptions as well as common esteem metrics such as citation rates. It is interesting to note then that there were much greater open access changes in the higher ranked journals, perhaps a reflection on their increased business model flexibility.

It is clear that open access to journals is undergoing a period of change. Consumers and contributors of research journals cannot take for granted which journals are open and which are closed, and no doubt publishers will market the open access opportunities as it evolves. This is especially true as there is evidence that open access provides a citation advantage [21] for contributors, which is likely to translate to an increase in the number of times an article is viewed or read, an advantage for the consumers as well as publishers. However, open access alone is not enough to maximise the reach of developing knowledge, accessibility is also about communication and meaningful expression of research [24]. It is also of utmost importance that the impact of open access journals is rated and further research into the feasibility of such a rating is highly recommended. Whilst some fields of research are increasingly tracking trends in open access, little is known about the exercise sciences. The exercise sciences however play an important role in society through the mass popularity of sporting competitions, to the major influence physical activity patterns play in chronic disease prevention. Thus, the importance of knowledge sharing and access issues in this field remains important in society and, much more work in this area is needed in the future.

In conclusion, it can be seen that a very small proportion of Exercise Science related journals (8.6\%) are fully open access. However there has been a shift and the comparison between 2010 and 2012 reveals an overall $11 \%$ increase in the number of journals that provide open access (or at least partial access) in the area of Exercise Science. This provides the consumer with the option to replicate and share the information freely. Publishing in open access journals is a modern trend unlikely to be reversed and it appears that from
2010 to 2012 business models are increasing in their accommodation of open access options.

\section{CONFLICT OF INTEREST}

The authors confirm that this article content has no conflicts of interest.

\section{ACKNOWLEDGEMENT}

Declared none.

\section{REFERENCES}

[1] Swan A. Open access: why should we have it? 2006. Available from: http://www.keyperspectives.co.uk/openaccessarchive/Jounalpublications/Belgian\%20library\%20journal\%20article $\% 20$ -

$\% 20$ final\%20revised\%20version.pdf [cited: $28^{\text {th }}$ June 2012].

[2] Pappalardo KM, Fitzgerald BF, Fitzgerald AM, Kiel-Chisholm SD, Georgiades J, Austin AC. Understanding open access in the academic environment: a guide for authors. 2008. Available from: http://eprints.qut.edu.au/14200/3/Understanding_Open_Access_in_an_ Academic_Environment-_A_Guide_for_Authors_[web_version].pdf [cited: $2^{\text {nd }}$ July 2012].

[3] Heath NIo. The omnibus appropriations act of 2009 makes the NIH public access policy permanent. 2009. Available from: http://grants.nih.gov/grants/guide/notice-files/NOT-OD-09071.html [cited: $2^{\text {nd }}$ July 2012].

[4] UK RC. Research Councils UK Policy on Access to Research Outputs. 2012. Available from: http://www.rcuk.ac.uk/documents/documents/RCUK\%20_Policy_on_Access_to_Research_Outputs. pdf [cited: $3^{\text {rd }}$ August 2012].

[5] DiCenso A. Evidence-based nursing practice: How to get there from here. Nursing Leadership 2003; 16(4): 20-6.

[6] Ciliska D, Thomas H, Buffett C. A compendium of critical appraisal tools for public health practice. 2008. Available from: http://www.empho.org.uk/Download/Public/11615/1/CA\%20Tools $\% 20$ for $\% 20$ Public $\% 20$ Health.pdf [cited: $28^{\text {th }}$ July 2012].

[7] Cullen R, Litt M. In search of evidence: family practitioners' use of the Internet for clinical information. J Med Libr Assoc 2002; 90(4): 370-9.

[8] IOC. Olympic Charter. 2011 Available from: http://www.olympic.org/Documents/olympic_charter_en.pdf. [cited: $24^{\text {th }}$ September 2012].

[9] Budapest open access initiative 2002. Available from: http://www.soros.org/openaccess/read [cited: $2^{\text {nd }}$ July 2012].

[10] Bail K, Ranse J, Clarke R, Rattray B. Open access to nursing journals: an audit of the 2010 ERA journal list. Australian J Adv Nursing 2012; in press.

[11] Libraries LU. Directory of open access journals. 2012. Available from: http://www.doaj.org/doaj?func=subject\&cpid=23 [Cited: $16^{\text {th }}$ May 2012].

[12] Thede LQ, Sewell JM. Informatics and nursing: competencies and applications. 3rd ed. Philadelphia, PA: Lippincott Williams \& Wilkins 2010.

[13] Sudsawad P. Knowledge translation: introduction to models, strategies and measures. Austin, TX: Southwest educational development laboratory, national center for the dissemination of disability research. Available from: http://198.214.141.98/kt/products/ktintro/index.html [cited: August 2007].

[14] Kermode S, Roberts K. Quantitative research designs. In: Taylor B, Kermode S, Roberts K, Eds. Research in nursing and health care: evidence for practice. $3^{\text {rd }}$ ed. Cengage Learning Australia 2006.

[15] Council AR. ERA 2010 Ranked Journal List. Australian Res Council 2010. Available from: http://www.arc.gov.au/era/era_2010/archive/era_journal_list.htm [cited: $2^{\text {nd }}$ October 2010].

[16] Carr Media release 2011. Available from: http://archive.innovation.gov.au/ministersarchive2011/Carr/MediaReleases/Pages/IMPROV EMENTSTOEXCELLENCEINRESEARCHFORAUSTRALIA.ht ml [cited: $30^{\text {th }}$ July 2012].

[17] Commons C. About the licenses. 2011 Available from: http://creativecommons.org/licenses/ [cited: $14^{\text {th }}$ September 2012].

[18] Laakso M, Welling P, Bukvova H, Nyman L, Björk BC, Hedlund T. The development of open access journal publishing from 1993 to 2009. PloS one $2011 ; 6(6)$ : e20961.

[19] argouri Y, Lariviere V, Gingras Y, Carr L, Harnard S. Green and gold open access percentages and growth, by discipline. 2012. Available from: arXiv: $1206.3664 \mathrm{v} 1$ [cited: $14^{\text {th }}$ September 2012]. 
[20] Björk BC, Welling P, Laakso M, Majlender P, Hedlund T, Guðnason G. Open access to the scientific journal literature: situation 2009. PloS one 2010; 5(6): e11273.

[21] Swan A. The open access citation advantage: studies and results to date. 2010 Available from: http://eprints.soton.ac.uk/id/eprint/268516 [cited: $5^{\text {th }}$ July 2012].

[22] Gargouri Y, Hajjem C, Larivière V, et al. Self-selected or mandated, open access increases citation impact for higher quality research. PLoS One 2010; 5(10): e13636.
[23] Björk BC, Solomon D. Open access versus subscription journals: a comparison of scientific impact. BMC Med 2012; 10(1): 73.

[24] Moscovitch B. Open access is not enough; we must learn how to communicate our research to make it truly accessible. 2012. Available from: http://blogs.lse.ac.uk/impactofsocialsciences/2012/05/17/open-access-not-enough-communication/ [cited: 20 ${ }^{\text {th }}$ July 2012].

Received: September 26, 2012

(C) Rattray et al.; Licensee Bentham Open.

This is an open access article licensed under the terms of the Creative Commons Attribution Non-Commercial License (http://creativecommons.org/licenses/ by-nc/3.0/) which permits unrestricted, non-commercial use, distribution and reproduction in any medium, provided the work is properly cited. 